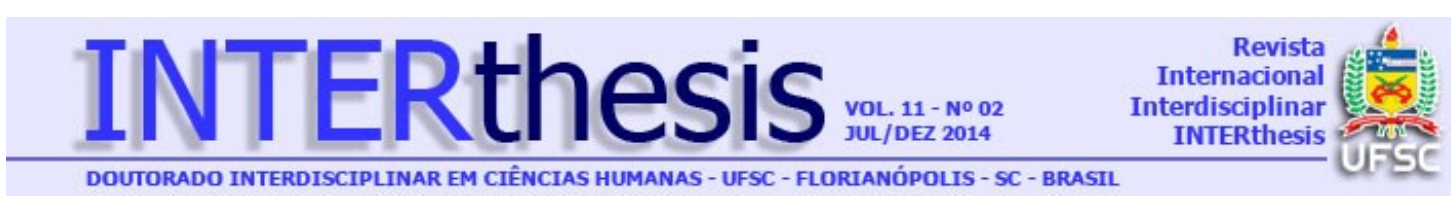

\title{
REMANESCENTES DO CONTESTADO EM TAQUARUÇU: DA INVISIBILIZAÇÃO HISTÓRICA AO RECONHECIMENTO SOCIAL COMO SUJJEITOS DE DIREITOS
}

\author{
Onete da Silva Podeleski ${ }^{1}$ \\ Valmir Luiz Stropasolas ${ }^{2}$
}

\section{Resumo:}

As populações tradicionais e camponesas no Brasil vivenciam, historicamente, a invisibilização e a exclusão social, processo este estreitamente vinculado com a falta de reconhecimento e valorização da sua identidade social e cultural na sociedade, acarretando enormes dificuldades para segmento expressivo dessa população acessar políticas públicas e direitos de cidadania. Este artigo aborda um segmento específico que é também afetado por essas problemáticas, os remanescentes da Guerra do Contestado em Santa Catarina, e se propõe analisar os principais fatores que dificultam a reprodução social desse público, os aspectos implicados na (re)definição de sua identidade social e na busca do reconhecimento como sujeitos de direitos na sociedade contemporânea. Para isso, fundamenta-se nos resultados de uma dissertação de mestrado elaborada a partir de um estudo de caso feito com famílias típicas desse grupo social em que se utilizou métodos qualitativos de investigação à luz de princípios da etnografia, de categorias da história, da sociologia e da agronomia, visando um diálogo interdisciplinar para dar conta de uma problemática social complexa e de grande importância não só para o território estudado como também para Santa Catarina. As questões relativas aos remanescentes do Contestado precisam ser incluídas nos estudos e pesquisas das mais diversas áreas do conhecimento, bem como nas prioridades das políticas que incidem em nível local, sob pena de continuarmos negando a sua existência como cidadãos e corroborando com a sua invisibilização social.

Palavras-chave: Inclusão social. Remanescentes do Contestado. Identidade. Reconhecimento social. Direitos de cidadania.

\section{INTRODUÇÃO}

Questões de marginalização e pobreza no meio rural se arrastam na história do Brasil e continuam na esfera das preocupações políticas contemporâneas. Nas últimas décadas, ganharam maior expressividade em decorrência das ações

\footnotetext{
1 Mestre em Agroecossistemas pela Universidade Federal de Santa Catarina, Florianópolis, SC, Brasil. E-mail: podeleski@hotmail.com

2 Doutor em Ciências Humanas pela Universidade Federal de Santa Catarina, e pós-doutorado em Sociologia da Infância pela Universidade do Minho, Portugal. Professor adjunto da Universidade Federal de Santa Catarina, Florianópolis, SC, Brasil. E-mail: valmir.stropasolas@ufsc.br
}

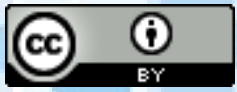
Esta obra foi licenciada com uma Licença Creative Commons - Atribuição 3.0 Não Adaptada. 
coletivas dos movimentos sociais do campo ao buscarem continuamente o acesso aos direitos de cidadania para as populações rurais e camponesas dos mais diversos territórios do país. O Movimento dos Trabalhadores Rurais Sem Terra MST é, atualmente, o movimento social de maior expressividade no Brasil. No entanto, além desse movimento que reivindica, sobretudo, o acesso à terra e condições adequadas para a produção de alimentos, outros movimentos sociais rurais eclodiram na história recente do Brasil e, ainda hoje, carecem de estudos e políticas que possibilitem o seu reconhecimento e inclusão social, valorizando suas demandas sociais represadas ao longo de suas trajetórias.

Um desses movimentos - abordado nesse artigo - eclode no período histórico reconhecido como Guerra do Contestado, cujo combate armado ocorre no interior do estado de Santa Catarina no período entre 1912 a 1916. Esse movimento se deu na primeira república (1890-1930), momento em que as divisas territoriais estavam ainda em disputas em SC, num primeiro momento, delimitações de fronteiras com a "Argentina" e, posteriormente, "entre SC e Paraná" (CÂMARA, 2013, p. 19-20). Foi um movimento que teve um líder religioso, sendo tratado por alguns autores - Duglas T. Monteiro e Maurício V. Queiroz -, como "movimento messiânico".

Mais recentemente, outras análises foram feitas sobre o movimento do Contestado, dando luz a uma nova perspectiva de análise, como a do historiador Paulo Pinheiro Machado (2007, p. 26), que trata o Contestado como um "movimento de cunho político", entre outras motivações, devido à ligação com as questões de demarcações territoriais, disputa entre elites políticas, coronelismo e desapropriações de moradores locais pelo interior de SC. Fatos que vinham ocorrendo desde a instauração da política de terras (BRASIL, Lei $n^{\circ}$ 601/1850) no Brasil Imperial, na qual o processo de colonização na região sul teve grande impulsividade, corroborando as novas questões de disputas sociais e políticas que foram surgindo na transição do Império (1822-1889) para a República (a partir de 1889).

Na província catarinense foi instituída a "Lei $n^{\circ} 173$, de 30 de setembro de 1895, que previa a legitimação e a revalidação de posses num prazo que se estendia até 1903" (MACHADO, 2007, p. 141). No entanto, a eficácia da legislação sobre a demarcação e registros das terras, tanto provinciais como nacionais,

R. Inter. Interdisc. INTERthesis, Florianópolis, v.11, n.2, p.204-228, Jul-Dez. 2014
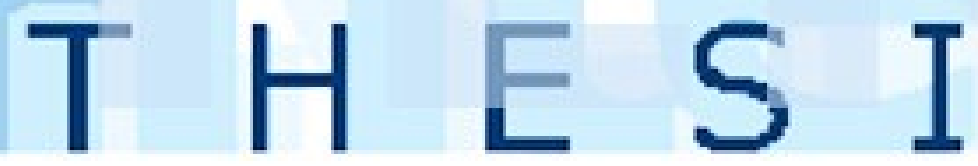
seguiram os mandos e desmandos dos donos dos poderes - proprietários de terras e políticos.

Em Santa Catarina, o aparato administrativo estava concentrado nas zonas litorâneas, ficando o restante do território a mandos do coronelismo ${ }^{3}$. As questões sobre os domínios territoriais locais só foram aumentando com o passar do tempo, a "grilagem e violência" (MACHADO, 2012, p. 15) pelos poderosos foram as práticas escolhidas para controlar os sertões catarinenses e assim muitos conquistaram poderes e outros foram sendo cada vez mais empobrecidos, destituídos dos seus meios de sobrevivência, principalmente os pequenos posseiros que não pactuavam do novo dispositivo de registrar as terras, pois seus interesses não estavam atrelados ao valor de mercadoria que desse modo era instituída e, também pela questão cultural, uma vez que, até então, o seu uso da terra se dava através de práticas de uso comum, onde não havia necessidade de demarcações, pois os vizinhos compartilhavam dessa ideia do modo de criação "aberta".

Outro fator colaborador na grilagem de terras e expulsão das populações locais foi a construção da Estrada de Ferro São Paulo-Rio Grande, que cruzava os sertões catarinenses e onde o governo deu vastas concessões de terras, sem qualquer menção às pessoas que viviam nessas áreas, à empresa Brazil Railway Company (BRC), originária dos Estados Unidos da América do Norte. Contexto este em que a entrada de capital estrangeiro também estava amplamente efervescente no final do século XIX. A necessidade da construção da estrada de ferro fora vista como de suma importância, pois proporcionaria uma ligação importante entre o centro e o sul do país, através do transporte de pessoas e mercadorias, além de impedir as incursões dos países vizinhos nessa faixa de fronteira. Talvez o uso mais efetivo dessa ferrovia tenha sido para a Guerra do Contestado, servindo para auxiliar no tráfego das tropas do exército para a região, através do "deslocamento de sete mil homens" (ESPIG, 2012, p. 218), sendo esses apenas alguns fatores do contexto que levou à eclosão da Guerra do Contestado, a partir de 1912.

\footnotetext{
${ }^{3} \mathrm{O}$ coronel era uma espécie de mediador entre os políticos locais e a população, sobretudo, a mais carente, em troca de privilégios particulares. "[...] enquanto chefe político municipal, o coronel era uma figura central nas lutas que por ventura ocorressem nos municípios onde exercia seu controle, inclusive nas disputas em torno de questões de terras. [...] os coronéis tiveram uma participação destacada nas manifestações violentas que abalaram os sertões no período em pauta" (SILVA, 1996, p. 258).
}

R. Inter. Interdisc. INTERthesis, Florianópolis, v.11, n.2, p.204-228, Jul-Dez. 2014 
Nessa problemática social que afeta até hoje as populações locais, pesquisamos um grupo de famílias remanescentes do movimento do Contestado em SC, a partir de um estudo de caso na comunidade de Taquaruçu, pertencente ao município de Fraiburgo, visando analisar os fatores implicados na reprodução socioeconômica e cultural desse público, abordando aspectos relevantes vinculados ao reconhecimento social dessa população e à identidade de remanescentes do Contestado.

\section{METODOLOGIA DA PESQUISA}

A seleção da problemática analisada e da localidade do estudo deu-se a partir de uma pesquisa bibliográfica exploratória, que nos chamou a atenção de como eram identificados os participantes populares deste movimento - fanáticos, jagunços, rebeldes, bandidos -, ou seja, noções usadas com um forte sentido pejorativo, evidenciando a produção de representações que inferiorizava um determinado segmento social, num contexto de conflito armado. Entre as localidades com uma importante atuação do movimento, entre as quais Irani, Caraguatá e Santa Maria, destaca-se a comunidade de Taquaruçu onde ocorreram os principais embates armados. Seria este o reduto que se reorganizou para o retorno do monge, agregando um número expressivo de pessoas nessa comunidade, ou seja:

Até o final de dezembro de 1913 tinham afluído mais de 800 pessoas para Taquaruçu, eram oriundos de diferentes distritos do interior do município de Curitibanos, além de alguns moradores provenientes de Campos Novos, Lages e Canoinhas (MACHADO, 2010, p. 17).

Este trabalho foi elaborado a partir de uma pesquisa qualitativa realizada na comunidade de Taquaruçu, localizada na zona rural do município de Fraiburgo, em Santa Catarina, ao sul do Brasil.

A base para a coleta das informações foram entrevistas semiestruturadas que levaram em consideração os princípios metodológicos que fundamentam a pesquisa etnográfica ${ }^{4}$, entrevistas estas realizadas em 2013. Os entrevistados foram definidos

\footnotetext{
${ }^{4}$ A etnografia, metodologia descritiva e analítica utilizada por praticantes da antropologia cultural, se constitui de [uma] observação participante, que consiste em um método para elaborar um discurso sobre um grupo cultural, ou espaço particular, ou um problema social, possível pelo envolvimento da pesquisadora no universo proposto para a pesquisa, e de momentos de descrição e análise da experiência de observação, posicionando aquilo que foi interpretado dentro de um contexto cultural
}

R. Inter. Interdisc. INTERthesis, Florianópolis, v.11, n.2, p.204-228, Jul-Dez. 2014
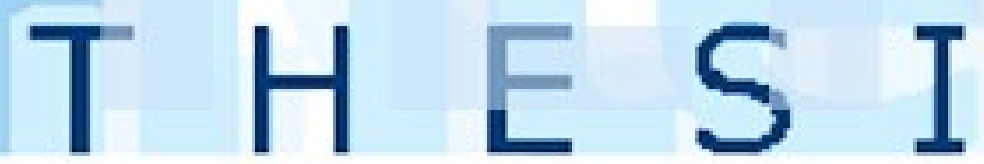
de maneira aleatória, no entanto, como critérios básicos deveriam ser remanescentes do Contestado e moradores atuais de Taquaruçu. Para a realização das entrevistas todos os entrevistados assinaram os termos de consentimento visando o uso acadêmico ${ }^{5}$ das informações coletadas à campo.

Embora sendo inserida por uma pessoa conhecida da comunidade, o que facilitou o acesso ao campo de coleta das informações, isso não impediu a desconfiança dos atores locais considerando a complexidade e os constrangimentos vinculados à problemática analisada, ao envolver seus antepassados, estigmas e desigualdades étnicas e sociais que ainda se reproduzem entre os moradores dessa comunidade. Facilmente se observa que existe uma divisão entre os "remanescentes do Contestado", tradicionalmente identificados como caboclos, e os "descendentes de imigrantes italianos".

Isso leva a refletir sobre as palavras de Malinowski, quando o autor descreve o seu trabalho de campo mencionando que:

[...] suas fontes de informação são, indubitavelmente, bastante acessíveis, mas também extremamente enganosas e complexas; não são incorporadas a documentos materiais fixos, mas sim ao comportamento e memória de seres humanos (1978, p. 23).

Ou seja, conquistar a confiança dos remanescentes foi um trabalho realizado no dia a dia da permanência no local que, sem sombra de dúvidas, foi o método fundamental para possibilitar alguns relatos, distante do gravador, que são norteadores dos complexos sentimentos que existem com seus antepassados e as condições em que vivem atualmente. Condição esta marcada, sobretudo, pelo trabalho de bóia-fria em períodos sazonais da agricultura local, fonte de renda principal para o sustento de suas famílias.

mais amplo. VENSON, A. M., PEDRO, J. M. Memórias como fonte de pesquisa em história e antropologia. História Oral (Rio de Janeiro), v. 15, 2012, p. 129-130.

5 Para a transcrição das entrevistas utilizou-se o apoio do software "Express Scribe", que tem download gratuito na internet. Ele auxilia na transcrição de arquivos sonoros, principalmente porque permite controlar a velocidade do arquivo sonoro contribuindo para maior agilidade no trabalho de transcrição para versão textual.

R. Inter. Interdisc. INTERthesis, Florianópolis, v.11, n.2, p.204-228, Jul-Dez. 2014
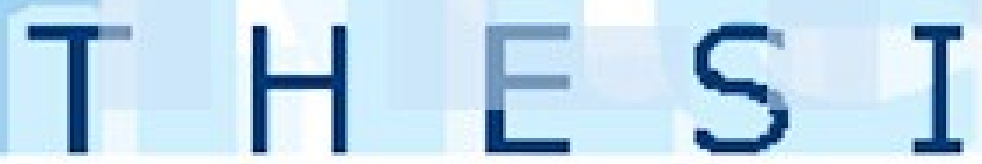


\section{OS REMANESCENTES DO CONTESTADO EM TAQUARUÇU}

Com a permanência na comunidade $^{6}$, algumas observações puderam ser realizadas com mais aprofundamento. Cabe salientar que tivemos dificuldades para conseguir informações sobre esta população junto às instituições do município como, por exemplo, o levantamento populacional de Taquaruçu.

De acordo com os moradores, vivem atualmente (Diário de campo, Jul./13) em Taquaruçu cinquenta e quatro famílias. Dessas, vinte famílias são remanescentes do Contestado, sendo que todas foram visitadas, visto que estão localizadas muito próximas. Foi necessário fazer um processo "inverso", buscando diretamente na própria comunidade seus dados constitutivos devido à dificuldade de obtenção dessas informações oficiais via instituições municipais.

A agricultura familiar está ganhando notoriedade nas últimas décadas, recebendo políticas fomentadoras que contribuem para a busca de continuidade da família no campo e ao seu auto-sustento. No entanto, além dessas categorias do meio rural, há uma que segue marginalizada, que são os casos específicos de trabalhadores no meio rural, identificados como "boia-fria, peão, diarista". Estas categorias sociais que ainda permanecem, de maneira geral, excluídas das políticas públicas ou mesmo insatisfatoriamente abordadas nas pesquisas, inscrevem-se num conjunto diverso de sujeitos do campo que Fraser (2002, p. 12) denomina de "trabalhadores temporários e a tempo parcial". Para a autora, essa atual população diversificada de trabalhadores tem extrema consciência das múltiplas hierarquias de estatuto, na medida em que seguem realizando as atividades para terceiros, grande parte deles sem vínculos oficiais trabalhistas, principalmente porque em sua maioria estão vinculados ao trabalho de produção sazonal, tornando-se núcleos de moradores periféricos aos agricultores familiares. Quando não visualizam uma igualdade de oportunidades no campo, podem deslocar-se para a cidade em busca de melhores condições de vida.

\footnotetext{
${ }^{6}$ A comunidade camponesa existe também em função de um sentimento de pertencimento a um grupo, de uma identidade coletiva e do compartilhamento de saberes, práticas e, sobretudo, valores que a constituem [...] Forman (1979, p. 282) [afirma] que a religião favorece o fortalecimento de laços interpessoais e, ao mesmo tempo, reforça "as noções de submissão e obrigação que marcam a ideologia do camponês brasileiro" (SABOURIN, 2009, p. 51); [...] No entanto, vários estudos feitos em comunidades rurais mostram que a solidariedade e a igualdade que caracterizam tais comunidades são indissociáveis de uma dimensão conflitiva, como dois lados de uma mesma moeda. (MOTTA, 2005, p. 117).
}

R. Inter. Interdisc. INTERthesis, Florianópolis, v.11, n.2, p.204-228, Jul-Dez. 2014
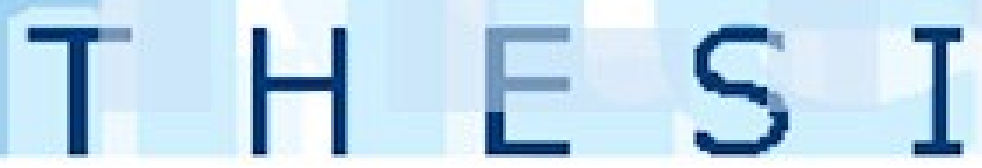
$\mathrm{Na}$ comunidade, verificam-se dificuldades estruturais básicas, algumas se encaminhando para casos de pobreza rural, que não devemos restringir e sim, aprofundar, enquanto concepções de análise, para "concepções mais abrangentes", pois, nas palavras de Mattei (2012, p. 2),

[...] esse "fenômeno [...] não deve se restringir apenas à privação de renda, mas também à privação de outros bens materiais e de acesso aos serviços sociais essenciais, especialmente nas áreas de saúde, educação, alimentação, nutrição, habitação e saneamento básico".

Ainda que seja possível acompanhar um processo de modernização na estrutura agrária do país, há uma trajetória pautada num modelo histórico de exclusão "[...] como a concentração da terra, as relações seculares de dominação e de expropriação do trabalho pelo capital" (MATTEI, 2012, p. 3).

Isso nos leva a constatar que, em Taquaruçu, ademais das questões limitadoras aferidas diretamente da situação de renda, há uma grande diferença de "nascimento" entre os remanescentes do Contestado e os descendentes de migrantes italianos, ou seja, o remanescente já nasce com uma realidade limitada de acesso ao capital, aos bens culturais e às condições de moradia. Entre aqueles que nascem dentro do núcleo familiar, isso se reflete diretamente na trajetória que visa o acesso à cidadania plena, nesse caso completamente desigual e diferenciada, pois o caminho para alcançar essas conquistas sociais é trilhado com dificuldades sociais e econômicas reproduzidas já dentro do próprio núcleo, pela tradição familiar de invisibilidade e exclusão social.

O mesmo não ocorre com os descendentes de migrantes italianos na mesma comunidade, pois esses, em sua maioria, são agricultores familiares que, embora passem por dificuldades no processo de desenvolvimento rural, o caminho trilhado para ter acesso aos recursos públicos e aos direitos de cidadania é mais curto. Todas estas propriedades possuem áreas que permitem realizar uma agricultura familiar, ainda que de pequena escala, mas permitindo o acesso a boas moradias, produção agrícola própria, possibilidades para que os(as) filhos(as) prossigam seus estudos, compra de algum maquinário ou equipamento para a produção, participação em atividades sociais em diversas localidades, entre outros.

Salientamos que essas hierarquias e desigualdades sociais, embora tenham se acentuado com a modernização do campo, estão arraigadas na história do Brasil e foram reproduzidas social e politicamente ao longo das gerações, processo em

R. Inter. Interdisc. INTERthesis, Florianópolis, v.11, n.2, p.204-228, Jul-Dez. 2014
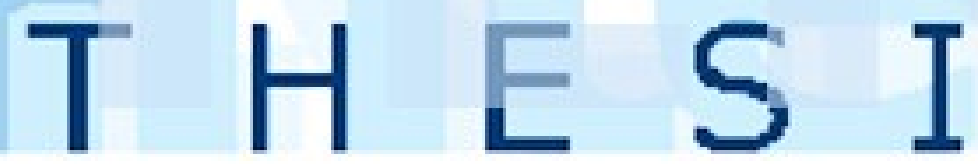
que os imigrantes tiveram um diferencial em relação ao acesso à terra e aos instrumentos para a produção (créditos, insumos, assistência técnica, etc.), mesmo onde haviam pequenas populações locais já instaladas. Esse modelo se reproduziu na forma de desigualdades que até hoje não foram compensadas; foram produzidas outras formas paliativas de sobrevivência com os programas sociais instalados no Brasil em grande escala.

Isso não significa dizer que aos remanescentes está proibido um cenário diverso, mas eles já nascem num contexto de "limitações" no seu estatuto social, o qual deveria ser a engrenagem para obter os direitos de cidadania como, por exemplo, os recursos do Programa de Abastecimento da Agricultura Familiar PRONAF, que não podem acessar devido às exigências das instituições bancárias, como a comprovação da propriedade da terra. Isso demonstra como as políticas públicas podem ser limitadoras do acesso a recursos por determinadas populações, na medida em que se apresentam difíceis de compreensão e de acesso devido aos seus modos de vida e de reprodução social.

Atualmente, os remanescentes vivem em um pedaço de terra ${ }^{7}$ que está fragmentado entre as famílias por herança, servindo de moradia, não como um direito de acesso à terra que permita a sua reprodução através da produção agrícola, conforme nos testemunha os entrevistados, casal Bernadete e Bernardo ${ }^{8}$ (f./m., 28/38 anos):

Uma parte muito pequena de terreno e onde tem o terreno é muito cheio de casas, que pode olhar aqui, tem quatro alqueires, faça a conta, tem onze moradores em cima do terreno.

Vê-se que os descendentes de migrantes italianos apresentam de maneira geral propriedades nas quais vive apenas uma família, havendo casos em que moram também os filhos que permanecem com os pais ou mesmo os avós. Ainda que eles estejam em pequenas propriedades, é possível realizar um processo de agricultura familiar gerador de renda, ou seja, além de uma subsistência familiar, se verificando uma qualificação dessa produção agrícola ou animal nestas propriedades, sobretudo nos casos em que se utilizam tecnologias modernas.

\footnotetext{
${ }^{7}$ Para esclarecer, uma família remanescente instala em quatro hectares e meio o montante de dez famílias, pois os descendentes estão se fixando em uma mesma propriedade.

8 Os nomes dos entrevistados foram omitidos para preservar sua verdadeira identidade e, as letras iniciais maiúsculas correspondem às mesmas identificações utilizadas na dissertação.
}

R. Inter. Interdisc. INTERthesis, Florianópolis, v.11, n.2, p.204-228, Jul-Dez. 2014
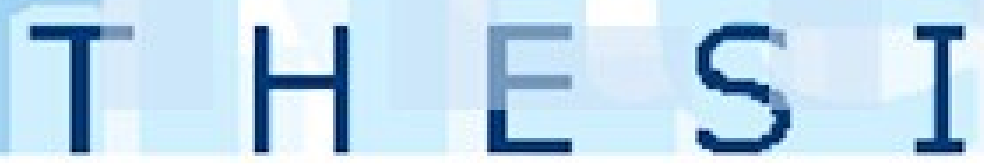
Já os remanescentes, que são boias-frias em plantações sazonais de alho e cebola na própria comunidade, em sua maioria, estão fadados a uma reprodução de subalternidade aos donos da terra e ao sistema político, pois não avançam em renda e nem no exercício de uma cidadania plena, literalmente, como nas palavras de um entrevistado, "trabalha de dia, para comer à noite (Entrevistados, casal Gabriela e Gabriel (f./m., 36/39 anos))".

Essa mesma perspectiva é a que vem sendo passada aos jovens, que não terminam a educação básica porque precisam ajudar na subsistência das suas famílias, mesmo existindo o ônibus escolar na comunidade. Em conversas com alguns jovens, percebe-se que o sistema de educação parece não estar contribuindo como uma alavanca nesse processo de autonomia no meio rural, pois não é o ato de estudar que é desestimulante - pois seria menos "sacrificante" que o trabalho nas lavouras -, mas o que fazer com uma educação ou uma qualificação, já que normalmente vêm exercendo a mesma função e tendo a mesma remuneração que os pais na condição de boias-frias.

Outro aspecto importante é que não há oportunidades de inserção socioeconômicas, especificamente postos de trabalho alternativos à condição encontrada de boias-frias, perspectiva essa já demonstrada em outros estudos sobre jovens no meio rural (Stropasolas, 2006, p. 168), em que se evidencia a existência de "um enorme e crescente isolamento social dos jovens que vivem nas comunidades rurais, bem como a ausência de organizações representativas e de apoio, sobretudo nos segmentos dos agricultores mais fragilizados".

Essa realidade negativa reproduz a falta de perspectivas dos jovens, com implicações no êxodo rural e nos problemas sociais já existentes nos centros urbanos, pois, sem uma mão-de-obra qualificada, também farão parte do contingente de operários e das favelas, ainda que a cidade sinalize uma melhor condição de renda, como indica um entrevistado: "[...] se quiser achar um serviço que ganhe mais tem que ir para a cidade. Na cidade a gente ganha um serviço melhor (Entrevistado Juliano (m., 18 anos))".

Nesse sentido, de um "mundo melhor" na cidade, outra entrevistada, se referindo à mesma diz "[...] daí as coisas seriam mais fáceis, teriam mais coisas. Nos finais de semana teria alguma coisa diferente para fazer, não ficar só em casa (Entrevistada Eliana (f., 16 anos))". Neste caso, aparece outro aspecto, que foi

R. Inter. Interdisc. INTERthesis, Florianópolis, v.11, n.2, p.204-228, Jul-Dez. 2014
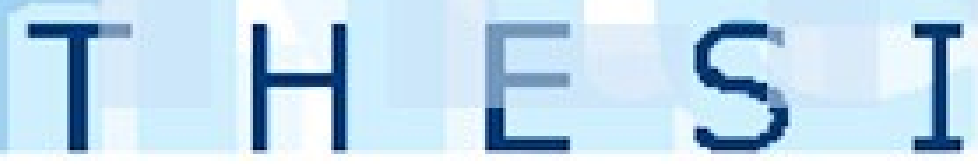
relevante nas falas de todos os contatos realizados, ou seja, a falta de lazer na comunidade, principalmente para os jovens. Muitos relataram que havia um campo de futebol ao lado da igreja da comunidade, mas que foi interditado pelas autoridades municipais para reforma e, há mais ou menos um ano, não deram continuidade ao trabalho começado. Todos acabam buscando diversão e esportes coletivos em outros municípios ou na parte urbana de Fraiburgo, quando podem, já que a zona urbana dista em torno de 26 quilômetros de Taquaruçu.

Com as dificuldades que Taquaruçu encontra nos acessos básicos a direitos como saúde, transporte público coletivo, lazer e educação, não poderiam ser diferentes a constatação de que parte de sua população, no caso os remanescentes, não tem o mínimo necessário nesses quesitos, sobretudo não acessando os espaços institucionais e os processos políticos que envolvem a produção agrícola e os bens culturais que poderiam contribuir na conquista de sua autonomia e na construção de uma vida social com mais igualdade.

Quando se analisam as questões que envolvem as condições sociais, o mercado de trabalho e as (precárias) alternativas de rendimentos por parte das famílias remanescentes, bem como as dificuldades de acesso a elementos fundamentais de cidadania (principalmente porque vem se transferindo às gerações mais novas os mesmos modelos excludentes), verificamos que são extremamente inadequados ou insuficientes os instrumentos de justiça social que poderiam criar as condições para promover a igualdade e a inclusão societária desses segmentos sociais rurais. Revisitando o conceito de justiça, Fraser (2002) considera que uma das vertentes desses instrumentos seria a "distribuição justa" e, no caso dos remanescentes pesquisados, poderíamos afirmar que:

[...] a quintessência da injustiça é a má distribuição, em sentido lato, englobando não só a desigualdade de rendimentos, mas também a exploração, a privação e a marginalização ou exclusão dos mercados de trabalho. Consequentemente, o remédio está na redistribuição, [...], abrangendo não só a transferência de rendimentos, mas também a reorganização da divisão do trabalho, a transformação da estrutura da posse da propriedade e a democratização dos processos através dos quais se tomam decisões relativas ao investimento (FRASER, 2002, p. 11).

Essa "má distribuição" vem sendo reproduzida desde o contexto vivenciado pelos seus antepassados, excluídos da terra, vitimados que são da Guerra do Contestado, vivendo com medo de armas, medo dos massacres retornarem, medo

R. Inter. Interdisc. INTERthesis, Florianópolis, v.11, n.2, p.204-228, Jul-Dez. 2014
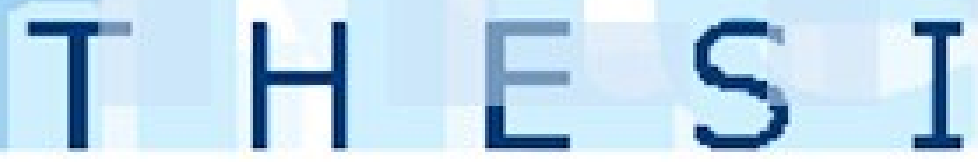
das autoridades; trazendo ainda hoje descrições dessas memórias, como pode ser visto nesta entrevista:

São coisas que marcaram muita gente, o pai [falecido] um tempo ficou meio variado da cabeça, sumiu de casa um monte de vezes para o mato, com medo. Que eles contavam, de certo ponham na cabeça e pensou que ia acontecer de novo (Entrevistados, casal Bernadete e Bernardo (f./m., 28/38 anos).

Persistindo essas memórias de mortes, crueldade com mulheres e crianças, ataque das forças armadas à comunidade, logicamente que eles não acreditam em um processo de inclusão coletiva à sua gente. Suas trajetórias vêm sendo de negação a conquistas, quaisquer que sejam elas.

Há programas que buscam hoje colaborar na inclusão social através da transferência de renda, como o Programa Bolsa Família e, em Taquaruçu, dos contatos realizados, somente os remanescentes estão cadastrados no programa. Se for tomado como um programa compensatório, segue mascarando, no mínimo, o período entressafras de desemprego dos bóias-frias. Medida essa que nem paliativamente se poderia afirmar que suprem as despesas de moradia e alimentação que um único filho pode dar aos seus pais.

\section{AS REDEFINIÇÕES NA IDENTIDADE DE REMANESCENTES DO CONTESTADO: DA INVISIBILIZAÇÃO HISTÓRICA AO RECONHECIMENTO SOCIAL COMO SUJEITOS DE DIREITOS}

A Guerra do Contestado teve diversos focos armados, onde os embates foram mais intensos, espalhados pelo interior do estado. Assim sendo, pensar em "remanescentes do Contestado" não pode estar limitado a Taquaruçu, como neste estudo de caso. No entanto, o processo de elaboração de uma identidade coletiva ou mesmo a formação de um movimento social no qual o objetivo seja atender a essa população, podem ser gerados, primeiramente, num dos núcleos dos vitimados pela guerra e, a partir daí, começarem as iniciativas para a reconstrução de uma identidade coletiva de remanescentes a fim de buscar a reconstituição de sua história e de seus direitos sociais.

Essa operacionalização também precisará contar com a intensificação da pesquisa científica para o mapeamento da população remanescente do Contestado no tempo presente, que também contribuirá na formação de novos pesquisadores

R. Inter. Interdisc. INTERthesis, Florianópolis, v.11, n.2, p.204-228, Jul-Dez. 2014
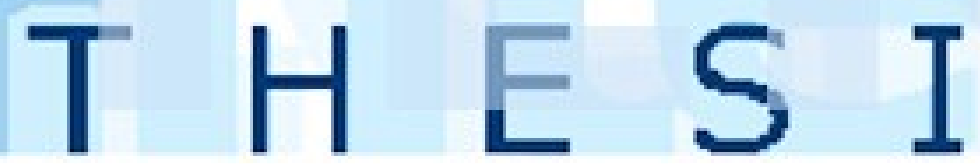
para as demandas sociais presentes em todo o Brasil. Essa colaboração tem a necessidade de ser conjunta com outras instituições governamentais para ter 0 devido reflexo e não cair no diálogo restrito dos pares científicos, pois a população em pauta tem uma trajetória histórica de exclusão, memórias de sofrimento da guerra e pobreza, que desarticula sua autonomia para quaisquer que sejam essas iniciativas de coletividade.

Como hipótese de trabalho, sugerimos que a primeira medida seja a incorporação de um reconhecimento ${ }^{9}$ social e jurídico como "remanescentes do Contestado" e não estritamente como "caboclos"10, pois esta categoria "caboclo" pode estar servindo de instrumento de "enfraquecimento" de atuação dessa população frente a outros grupos. Ou, como se referem ELIAS \& SCOTSON (2000, p. 24):

\begin{abstract}
Nesta situação, o estigma social imposto pelo grupo mais poderoso ao menos poderoso costuma penetrar na auto-imagem deste último e, com isso, enfraquecê-lo e desanimá-lo. Consequentemente, a capacidade de estigmatizar diminui ou até se inverte, quando um grupo deixa de estar em condições de manter seu monopólio das principais fontes de poder existentes numa sociedade e de excluir da participação nessas fontes outros grupos interdependentes.
\end{abstract}

O termo foi tradicionalmente usado para uma diferenciação étnica, que colaborou na colocação de sua história em segundo plano frente ao processo de colonização europeia de ocupação territorial, intensificada no Sul do Brasil até início do século XX, num mesmo sentido que deu o historiador Márcio A. B. da Silva (2004, p. 9-10) em seu trabalho sobre caboclos ao afirmar que "os caboclos ainda não receberam atenção proporcional a sua importância no processo de ocupação e constituição do Rio Grande do Sul".

Os estudos mais recentes trazem a terminologia cabocla a partir de concepções sociológicas e culturais, como nos trabalhos sobre a Guerra do Contestado, em suas diferentes linhas de análise. Nessa ampliação do uso do termo é que, neste trabalho de campo, foi verificado que os remanescentes do Contestado em Taquaruçu não se auto-identificam como caboclos, eles somente mencionaram o

\footnotetext{
${ }^{9}$ Admitir que eles existissem legalmente, jurìdicamente na sociedade brasileira.

10 No censo de 1872 a população foi classificada, do ponto de vista étnico, em: pardos, pretos, brancos e caboclos. Nesse caso, o caboclo se refere aos mestiços descendentes de índios e brancos, conforme o sentido literal da palavra na língua tupi. [...] Embora o conceito não seja puramente étnico, pode-se afirmar que o caboclo é, na imensa maioria, descendente de índios, portugueses pobres e africanos (ZARTH, 2002, p. 172).
}

R. Inter. Interdisc. INTERthesis, Florianópolis, v.11, n.2, p.204-228, Jul-Dez. 2014
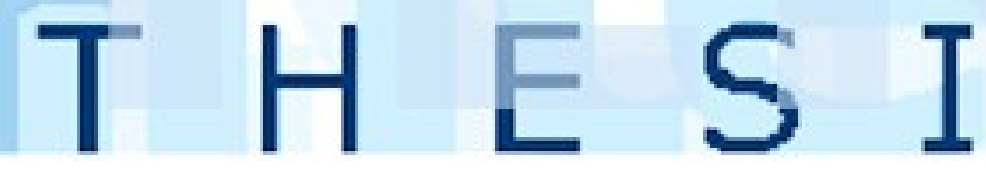
termo quando foram questionados sobre, pois a frequência do uso se percebeu por parte dos descendentes de migrantes de italianos, não parecendo usar um sentido discriminatório de raça [enquanto fenótipo], mas por não terem as mesmas raízes familiares em suas ascendências.

No entanto, a palavra "caboclo" sempre esteve atrelada a uso pejorativos de pessoas de descendência negra, lavrador pobre, sem origem e isso pode ser um dos aspectos do fato de os remanescentes não se identificarem com o termo, já que "a diferença, em si, deriva da sociedade, porque, em geral, antes que uma diferença seja importante ela deve ser coletivamente conceitualizada pela sociedade como um todo" (GOFFMAN, 1988, p. 134), ou seja, a estigmatização foi dada e não originada do que um caboclo considera ser "um tipo caboclo" na sua existência originária.

Mesmo quando reconhecem que "caboclos" eram seus antepassados - e mesmo se usado hoje, interpreta uma entrevistada, que "por causa da cor não é, porque daí já tem bastante mistura, é como caboclo mesmo ali, já é bem mais moreno (Entrevistada Helena (f., 52 anos))".

Mas este depoimento fez-se contraditório a outro, ou seja, "aqui todo mundo se relaciona bem, mas sempre tem aquela diferencinha [risos], é que os 'gringos' parecem ser diferentes, o modo de pensar, que a pele deles é mais clara [...] (Entrevistada Agostina (f., 28 anos))", assim, nem sempre há o apagamento das origens, sejam elas físicas ou sociais.

Mesmo que entre os remanescentes eles identifiquem a descendência cabocla, isso conscientemente não é motivação para salientar nos discursos, pois têm consciência do uso pejorativo da identificação pela sociedade e hoje buscam ter uma vida mais "homogênea" no espaço que estão inseridos, salientando sempre que a comunidade possui boas relações já que todos nasceram e se criaram ali, como aponta Bloemer (2000, p. 211) ao destacar que se criam vínculos de amizades também nesses espaços:

\footnotetext{
"Visinhar" com parente é o desejado, mas quando isso não ocorre, a relação que se estabelece entre os vizinhos é, [...] "como se fossem parentes". A amizade e a reciprocidade acontecem mesmo se tratando de vizinhos etnicamente diferentes.
}

Até mesmo retomar questões sobre reconhecimento social a partir da guerra é delicado para ambos os grupos, remanescentes ou descendentes de migrantes,

R. Inter. Interdisc. INTERthesis, Florianópolis, v.11, n.2, p.204-228, Jul-Dez. 2014
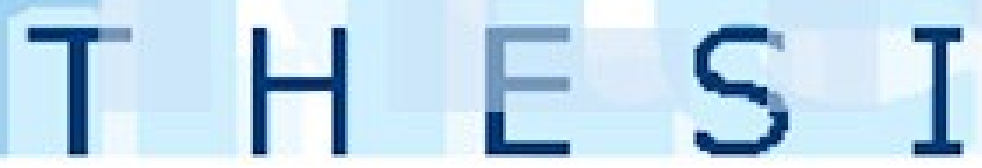
pois se estaria mexendo diretamente nas relações de boa vizinhança que estabeleceram e nas relações de poder que ali estão instaladas.

Essa "boa vizinhança" também está ligada às questões das relações de trabalho, que dentro de suas limitações, é o ponto de equilíbrio entre eles, pois uns são boias-frias e outros precisam da disponibilidade dessa mão-de-obra na sua produção agrícola.

Relações de poder que também se percebem nas tomadas de decisões na esfera da igreja católica, que é a religião fortemente seguida por todos na comunidade, mas principalmente pelos descendentes de migrantes italianos. Isso tem um peso muito forte na participação ativa da administração da igreja enquanto local central de sociabilidade na comunidade, do qual prevalecem à frente as famílias que contribuem economicamente e organizacionalmente com a manutenção da igreja, ou seja, "a religião continua a ser uma via de poder, ainda que de forma modificada" (RAFFESTIN, 1993, p. 127).

Essa constatação não significa dizer que os remanescentes estão impedidos de participarem de qualquer atividade, todavia não está cristalizada uma participação em igualdade de condições na parte administrativa.

Na concepção de Silva (2005), a afirmação da identidade e a enunciação da diferença traduzem $\mathrm{o}$ desejo dos diferentes grupos sociais, assimetricamente situados, de garantir o acesso privilegiado aos bens sociais. A identidade e a diferença estão, pois, em estreita conexão com relações de poder. O poder de definir a identidade e de marcar a diferença não pode ser separado das relações mais amplas de poder, em declarações sobre quem pertence e sobre quem não pertence, sobre quem está incluído e quem está excluído. Para o autor, a identidade está sempre ligada a uma forte separação entre "nós" e "eles". Essa demarcação de fronteiras, essa separação e distinção, supõem e, ao mesmo tempo, afirmam e reafirmam relações de poder, o que significa também classificar e dividir o mundo social, o que torna-se central na vida social, ou seja, a divisão e ordenamento da sociedade em grupos, em classes, que não são simples agrupamentos simétricos, mas também hierarquizações.

Logo, se é conferido aos remanescentes um reconhecimento jurídico, eles remanejam a sua configuração social, o qual poderá fazê-los sentirem-se ou de fato

R. Inter. Interdisc. INTERthesis, Florianópolis, v.11, n.2, p.204-228, Jul-Dez. 2014
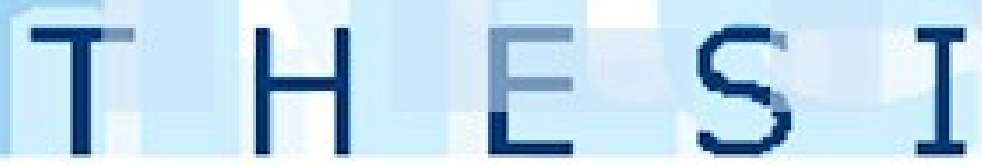
serem respeitados e contemplados em igualdade com quaisquer outras categorias sociais que têm hoje representatividade no meio em que se encontram.

$\mathrm{Na}$ luta pelo reconhecimento social e afirmação de uma identidade está envolvido um conjunto de fatores que se influenciam mutuamente e que não se restringem às iniciativas próprias dos indivíduos na sua trajetória em busca de afirmação social. Obviamente que, numa sociedade moderna, globalizada e fundamentada no individualismo exacerbado, os sujeitos são "estimulados" a encontrar reconhecimento como seres autônomos, individualizados, que disputam com outros indivíduos recursos simbólicos e materiais da sociedade. Como se refere Honneth (2003), na sua obra "Luta por reconhecimento", sem a suposição de uma certa medida de autoconfiança, de autonomia juridicamente preservada e de segurança sobre o valor das próprias capacidades, não é imaginável um êxito na autorrealização, se por isso deve ser entendido um processo de realização espontânea de metas de vida autonomamente eleitas.

Podemos verificar também em Honneth a distinção entre "conhecimento" e "reconhecimento" de um indivíduo ou grupo social. Enquanto a primeira noção se constitui num ato cognitivo não público, este último conceito se reveste de um ato expressivo em que pessoas ou agrupamentos sociais são considerados como possuidores de um valor social ${ }^{11}$.

No caso dos remanescentes, esse reconhecimento permite que os "outros", nós, também passemos a olhá-los a partir de outra perspectiva, como sujeitos históricos dotados de consciência política e de direito a uma cidadania plena tanto quanto a um descendente de migrante italiano, alemão, agricultor familiar, etc. Ou seja, uma visibilidade social concreta e não apenas como um fato histórico.

Casos exemplares, principalmente a partir da Constituição Federal de 1988 (BRASIL, 1988), ainda que de abrangência maior no território nacional, emergiram a partir dessa consciência coletiva e do reconhecimento jurídico por parte do Estado brasileiro e da sociedade, sendo esses relativos aos indígenas e quilombolas. Atente-se, porém, que, mesmo com um aparato legal, este não impede que o caminho trilhado não tenha problemas, ou como se refere Almeida (2004, p. 11): 11 Ver Oliveira (2006, p. 31), que faz uma abordagem mais detalhada desta distinção feita por
Honneth entre estes dois conceitos.

R. Inter. Interdisc. INTERthesis, Florianópolis, v.11, n.2, p.204-228, Jul-Dez. 2014 
Mesmo levando em conta que o poder é efetivamente expresso sob uma forma jurídica ou que a linguagem do poder é o direito, há enormes dificuldades de implementação de disposições legais desta ordem, especialmente em sociedades autoritárias e de fundamentos coloniais e escravistas, como no caso brasileiro.

Embora não estejam em sua plenitude, muito já foi alcançado por essas populações, bem como outras políticas de abrangência menor, criadas muitas vezes a partir de políticas locais ou regionais determinadas por meio do reconhecimento de "identidades coletivas" para casos específicos de populações e uso dos recursos naturais como são os de quebradeiras de coco babaçu, ribeirinhas, atingidos por barragens e faxinais.

A partir dessas populações mencionadas pode-se incorporar um conceito que vem sendo pensado na América Latina, que são as "neocomunidades", onde "agentes externos" e "comunidades populares" interagem diferentemente do isolamento dado às comunidades tradicionais no passado. Nesse direcionamento, "ao invés de participarem dos fluxos de desterritorialização e hibridação, as neocomunidades representam uma tendência à refundação de territórios tradicionais e à produção de "autenticidades" culturais delimitadas espacial e simbolicamente" (LIFSCHITZ, 2006, p. 68), ou seja, há um retorno ao passado pensado para "reconstruções de territórios, práticas e saberes" (LIFSCHITZ, 2006, p. 73).

Ou ainda, mesmo que algumas políticas sejam limitadas em certo grau de alcance, como aponta Sabourin (2009, p. 31) chamando de "institucionalização das populações tradicionais" ao se referir à Amazônia e aos quilombolas, é, por outro lado, uma maneira de que o Estado e a sociedade pactuem da viabilização da permanência desses no campo e alcancem sua autonomia na sustentabilidade familiar e ressarcimento por seus antepassados que perderam, inclusive, suas vidas, defendendo parte do território do estado de Santa Catarina, ou mesmo brasileiro, na divisa com a Argentina.

Nesse sentido de "institucionalização" o antropólogo Almeida (2004, p. 10), ao tratar de "terras tradicionalmente ocupadas" na Amazônia, aponta que as dificuldades existem e estão historicamente enraizadas, ao ponto que se fazem necessárias mudanças na estrutura social, mencionando que:

As dificuldades de definição destes dispositivos legais indicam, entretanto, que há tensões relativas ao reconhecimento jurídico-formal, sobretudo porque rompem com a invisibilidade social, que historicamente caracterizou estas formas de apropriação dos recursos baseadas principalmente no uso

R. Inter. Interdisc. INTERthesis, Florianópolis, v.11, n.2, p.204-228, Jul-Dez. 2014
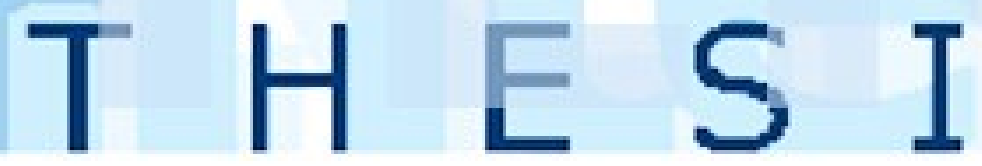
comum [da terra e recursos naturais] e em fatores culturais intrínsecos, e impelem a transformações na estrutura agrária.

Se uma reforma agrária que satisfaça a toda população do campo brasileiro ainda não é possível, então que um tratamento diferenciado aos casos mais emergentes seja proporcionado, pois, transcorridos cem anos da Guerra do Contestado em Santa Catarina, está na hora dessa população ganhar a devida atenção. Facilmente encontramos descrições ou relatos formais ou informais que mencionam a população remanescente do Contestado, tanto na academia como na sociedade em geral, compactuando sobre a sua existência em alguns espaços e, se eles resistem até hoje, porque não conceituá-los devidamente e oferecer o amparo legal correspondente a sua diversidade?

Alguns aparatos jurídicos contemporâneos já colaboram nos primeiros passos a serem dados em relação ao reconhecimento da população remanescente do Contestado, como recuperar o patrimônio cultural imaterial, desde o Decreto 3551/00 (Institui o Registro de Bens Culturais de Natureza Imaterial que constituem patrimônio cultural brasileiro, cria o Programa Nacional do Patrimônio Imaterial e dá outras providências), o qual visa a registrar o patrimônio cultural brasileiro a partir do registro de "conhecimentos e modos de fazer do cotidiano das comunidades, rituais e festas da vivência coletiva do trabalho, religiosidade, manifestações literárias, práticas culturais coletivas,..." Esses instrumentos ajudam a recuperar a formação identitária dos remanescentes a partir de práticas coletivas realizadas por seus antepassados e daquelas que ainda permanecem em sua comunidade, colaborando para o delineamento de sua etnicidade enquanto remanescente.

Outro Decreto que pode colaborar nesse processo é o de $n^{0} 6.040 / 2007$ (Institui a Política Nacional de Desenvolvimento Sustentável dos Povos e Comunidades Tradicionais), que apresenta a definição de povos e territórios tradicionais, aos quais os remanescentes poderiam recorrer no intuito de não apenas registrar suas práticas, mas de também serem reconhecidos como população que precisa ter o território que utilizaram para que essas mesmas dinâmicas de sua cultura e reprodução social possam continuar existindo e sendo passadas para as novas gerações.

R. Inter. Interdisc. INTERthesis, Florianópolis, v.11, n.2, p.204-228, Jul-Dez. 2014
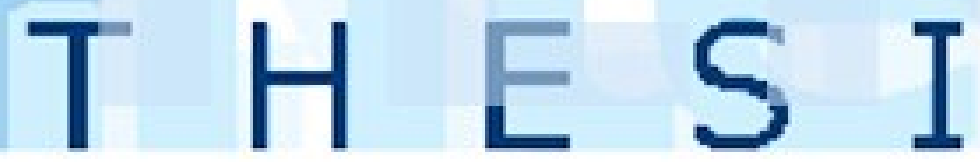
Colabora, nesse sentido, a Convenção sobre a Proteção e Promoção da Diversidade das Expressões Culturais (BRASIL, 2007), em que o Brasil também firmou acordo, tem por um de seus princípios diretores:

3. Princípio da igual dignidade e do respeito por todas as culturas: A proteção e a promoção da diversidade das expressões culturais pressupõem o reconhecimento da igual dignidade e o respeito por todas as culturas, incluindo as das pessoas pertencentes a minorias e as dos povos indígenas.

Os remanescentes do Contestado foram excluídos do direito de suas culturas tradicionais como a "criação de animais a solta" e, até hoje, ainda carregam aspectos negativos quanto às suas práticas e manifestações culturais e religiosas, como a "Recomenda das Almas". Sendo uma prática herdada de seus antepassados, essa procissão, realizada no período da quaresma, guarda cantos e rezas particulares de seu povo, não sendo acompanhada, com raras exceções, pelos demais membros da comunidade de Taquaruçu, o que demonstra não existir um compartilhamento intercultural desse rito, ou seja, a procissão. No entanto, não frequentar a igreja católica com a mesma assiduidade dos descendentes de migrantes é visto, por muitos, como certa indisciplina e não como de respeito a pessoas com diferenças culturais tão dignificantes quanto às demais práticas culturais de cunho religioso de qualquer outra população.

Essa Convenção prescreve práticas de igualdade que ainda não se encontram naturalizadas em nossa sociedade, no que já ocorreu com o candomblé, a capoeira, o luteranismo, necessitando que os grupos minoritários, principalmente, busquem o apoio junto a esse acordo internacional que foi reconhecido pelo governo brasileiro através do Decreto $n^{\circ} 6.177$ (BRASIL, 2007).

Outro aspecto legal é a lei $n^{\circ}$ 12.120/2002 (Cria o Programa Catarinense de Inclusão Social e adota outras providências) do estado de Santa Catarina, que foi criada para inclusão social e desenvolvimento dos municípios e populações menos favorecidas do estado, pelo que alguns locais já foram atendidos, num primeiro momento. No entanto, enquanto população minoritária, os remanescentes nem se quer receberam visitas de autoridades políticas durante as comemorações do centenário do Contestado, iniciadas em 2012, indicando que esses ainda não fazem parte das pautas políticas, nem de forma ampla dentro de políticas de assistencialismo, que dirá numa agenda de reconhecimento jurídico.

R. Inter. Interdisc. INTERthesis, Florianópolis, v.11, n.2, p.204-228, Jul-Dez. 2014
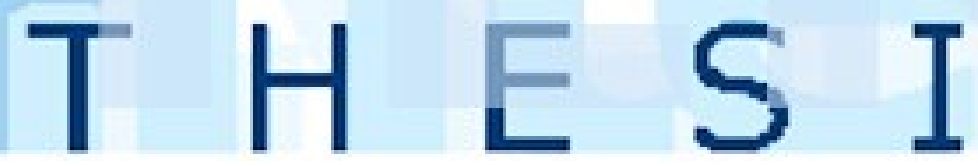
Nesse contexto, retomamos o que Fraser tratou de englobar na "distribuição justa" ao propor uma "integração de reconhecimento e redistribuição", que para haver justiça não é necessário que uma tenha que se sobrepor a outra, pois assim se teria uma "falsa justiça". Logo, na integração dessas, o reconhecimento se faz necessário, pois "[...] a injustiça surge na forma de subordinação de estatuto, assente nas hierarquias institucionalizadas de valor cultural" (FRASER, 2002, p. 12).

Ainda que existam outras legislações brasileiras que possam complementar essas possibilidades referidas aos remanescentes do Contestado, para serem plenamente incluídos nelas, há a necessidade de se construir uma política que dê conta de suas particularidades sociais e culturais, onde haja o entendimento de uma justiça social, ou seja:

[...] de forma a abarcar não só as reformas que visam revalorizar as identidades desrespeitadas e os produtos culturais de grupos discriminados, mas também os esforços de reconhecimento e valorização da diversidade, por um lado, e, por outro, os esforços de transformação da ordem simbólica e de desconstrução dos termos que estão subjacentes às diferenciações de estatutos existentes, de forma a mudar a identidade social de todos (FRASER, 2002, p. 12).

Essa nova proposta, de equiparação histórica de direitos, precisa ser construída em conjunto com esses sujeitos sociais, não se limitando apenas ao assistencialismo presente nas políticas sociais criadas a partir de demandas universais, que acabam somente tendo um papel paliativo e não de transformação das condições sociais enfrentadas por essa população, mas visando a construção de sujeitos ativos na participação social e política orientada para o seu reconhecimento e valorização social.

\section{CONSIDERAÇÕES FINAIS}

A partir da recuperação histórica de elementos implicados na reprodução social e na (re)definição da identidade de remanescentes entre as famílias pesquisadas na comunidade de Taquaruçu, podemos evidenciar alguns aspectos que permanecem na história local dessa população, entre os quais: a persistência da impossibilidade de acesso à terra, a reprodução socioeconômica pautada no trabalho de boia-fria, a descontinuidade na formação escolar, a falta de acesso aos recursos públicos como o PRONAF e suas políticas específicas. Enfim, uma

R. Inter. Interdisc. INTERthesis, Florianópolis, v.11, n.2, p.204-228, Jul-Dez. 2014
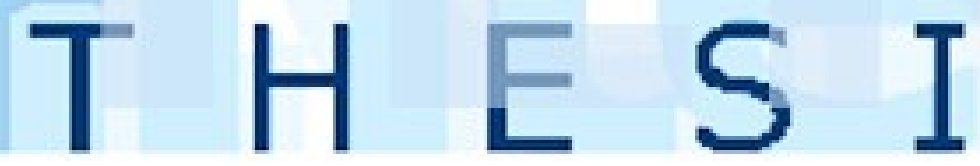
comunidade que fez parte de um palco de tamanha importância histórica continua esquecida junto às instituições públicas, seus dirigentes e projetos políticos. Uma população remanescente ainda invisibilizada em termos de reconhecimento legal pelas perdas e lutas de seus antepassados contributivos para a história local e nacional.

Ainda assim, eles continuam vivendo no local em que estavam seus antepassados, mesmo enfrentando grandes adversidades sociais e econômicas, ou seja, "o território usado" que Milton Santos (2005, p. 255) conceitua como "[...] objetos e ações, sinônimo de espaço humano, espaço habitado" e que permanece carregado das subjetividades desses atores, relembrando o heroísmo e o sofrimento do passado, que ainda está vivo nas memórias, principalmente dos remanescentes mais velhos. Por outro lado, os mais jovens estão descrentes de que possam melhorar a vida no meio rural ou que, algum dia poderão, ter seu reconhecimento, pois os mesmos afirmam que muitas pesquisas já foram realizadas com eles, no entanto continuam vivendo do mesmo jeito, nada foi implementado para mudar a sua condição social.

O nosso sistema político democrático permite a efetivação de novos dispositivos legais para equilibrar as adversidades entre Estado e sociedade e isso pode ser observado em termos de algumas conquistas nos casos de indígenas e quilombolas, embora seja sabido que estas populações ainda enfrentam enormes dificuldades para ter os seus direitos reconhecidos de fato. Mesmo havendo a implantação de uma política afirmativa aos remanescentes, esta não mexeu nos problemas estruturais vivenciados por essa população, que vivenciou trajetórias seculares de desigualdades, conflitos e exclusão. Atualmente, através do reconhecimento de sua existência, incorporando-se à sociedade o reconhecimento legal de sua identidade social de remanescentes do Contestado, pode-se mobilizar os instrumentos para a sua inclusão nos direitos de cidadania.

A Guerra do Contestado foi um evento social de grande envergadura política que acabou sendo determinante para o delineamento e fortalecimento do estado de Santa Catarina e já não há mais como negarmos esse fato histórico. No entanto, ao abordarmos os remanescentes do Contestado, esperamos que com os resultados da pesquisa realizada, sintetizada neste artigo, possamos estar contribuindo com subsídios para uma atuação eficaz do Estado e da sociedade brasileira no sentido

R. Inter. Interdisc. INTERthesis, Florianópolis, v.11, n.2, p.204-228, Jul-Dez. 2014
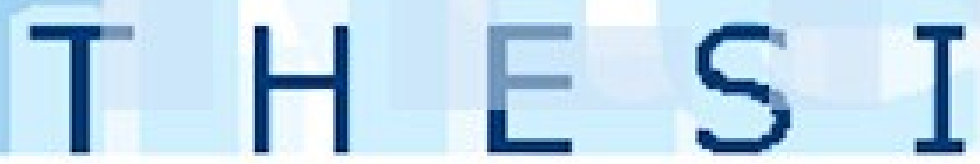
de haver o devido reconhecimento dessa população, ultrapassando assim a fronteira acadêmica para ser útil aos esforços necessários para saldar tão elevada dívida social que ainda se reproduz nesse território. Sobretudo, as questões relativas aos remanescentes do Contestado precisam ser incluídas nas prioridades das políticas que incidem em nível local, sob pena de continuarmos negando a sua existência como cidadãos e corroborando com a sua invisibilização social.

R. Inter. Interdisc. INTERthesis, Florianópolis, v.11, n.2, p.204-228, Jul-Dez. 2014

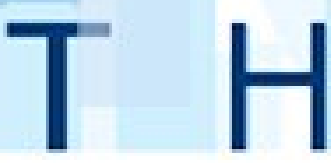




\title{
REMNANTS OF THE CONTESTADO WAR IN TAQUARUÇU: FROM THE HISTORICAL INVISIBILITY TO SOCIAL RECOGNITION AS SUBJECTS OF RIGHTS
}

\begin{abstract}
Traditional and peasant populations in Brazil experience, historically, the invisibility and social exclusion, a process closely linked with the lack of recognition and appreciation of their social and cultural identity in society. This issue causes enormous difficulties to an expressive segment of this population to access public policies and request citizenship rights. This article addresses a specific segment also affected by those issues, the remnants of the Contestado War in Santa Catarina. We propose analyzing the main factors that hinder the social reproduction of this people, the aspects involved in the (re) definition of their social identity and the search for recognition as subjects of rights in the contemporary society. It is based on results of a dissertation drawn from a case study done with typical families in their social groups, in order to realize a discussion on this complex social problem presented, highly important not only inside the study area, but also in the whole state of Santa Catarina. We have used qualitative research methods in the light of principles of ethnography, categories of history, sociology and agronomy, aiming at an interdisciplinary dialogue. Issues relating to the remnants of the Contestado War must be included in studies and research from various fields of knowledge as well as in the priorities of policies that focus on the local level, under penalty of continuing denying their existence as citizens and corroborating their social invisibility.

Keywords: Social Inclusion. Remnants. Contestado War. Identity. Social recognition. Citizenship rights.

\section{SOBREVIVIENTES DE LA GUERRA DEL CONTESTADO EN TAQUARUÇU: DE LA INVISIBILIZACIÓN HISTÓRICA AL RECONOCIMIENTO SOCIAL COMO SỦJETOS DE DERECHO}

\section{Resumen}

Las poblaciones tradicionales y campesinas del Brasil experimentan, históricamente,la invisibilización y exclusión social, proceso que está estrechamente vinculado a la falta de reconocimiento y valorización de su identidad social y cultural en la sociedad, lo que acarrea enormes dificultades para que un sector importante de esa población tenga acceso a políticas públicas y derechos de ciudadanía. Este artículo aborda un sector específico afectado por estas problemáticas, los sobrevivientes de la Guerra del Contestado en Santa Catarina, y se propone analizar los principales factores que dificultan su reproducción social de ese grupo social, los aspectos implicado en la (re)definición de su identidad social y en la búsqueda de reconocimiento como sujetos de derecho en la sociedad contemporánea. Para eso, se basa en los resultados de una tesis de maestría, elaborada a partir de un estudio de caso realizado con familias típicas de ese grupo social, en la cual se utilizaron métodos cualitativos de investigación, a la luz de los principios de la etnografía, y de categorías de la historia, la sociología y la agronomía, con el objetivo de constituir un diálogo interdisciplinar para dar cuenta de una problemática social compleja y de gran importancia, no solamente para el territorio estudiado, como también para Santa Catarina. Las cuestiones relativas a los sobrevivientes del Contestado deben ser incluidas en los estudios e investigaciones de diversas áreas del conocimiento, así como en las prioridades de las políticas que inciden a nivel local, so pena de continuar negando su existencia como ciudadanos y corroborando su invisibilización social.

Palabras clave: Inclusión social. Sobrevivientes del Contestado. Identidad. Reconocimiento social. Derechos de ciudadanía. 


\section{REFERÊNCIAS}

ALMEIDA, Alfredo Wagner Berno de. Terras tradicionalmente ocupadas: processos de territorialização e movimentos sociais. RJ: ANPUR, 2004.

BLOEMER, Neusa Maria Sens. Brava gente brasileira: migrantes italianos e caboclos nos campos de Lages. Florianópolis, SC: Cidade Futura, 2000.

BRASIL. Constituição Federal (1988). Constituição da República Federativa do Brasil. Brasília, DF: Senado Federal: Centro Gráfico, 1988.

BRASIL. Decreto $n^{\circ} 3.551$, de 04 de agosto de 2000. Institui o Registro de Bens Culturais de Natureza Imaterial que constituem patrimônio cultural brasileiro, cria o Programa Nacional do Patrimônio Imaterial e dá outras providências. Diário Oficial, Brasília, DF, [2000?].

BRASIL. Decreto $n^{\circ} 6.177$, de 01 de agosto de 2007. Promulga a Convenção sobre a Proteção e Promoção da Diversidade das Expressões Culturais, assinada em Paris, em 20 de outubro de 2005. Diário Oficial, Brasília, DF, [2007?].

BRASIL. Lei $n^{\circ}$. 601, de 18 de setembro de 1850. Dispõe sobre as terras devolutas do Império. Coleção de Leis do Império do Brasil (1808-1889) - Atos do Poder Legislativo, [1850?], p. 307-313.

CÂMARA, Maurício Ruiz. Formação territorial da Bela Santa Catarina. Revista Geográfica Catarina. Ano I, nº 01. SC: Editora Leão Baio, 2013.

Convenção sobre a Proteção e Promoção da Diversidade das Expressões Culturais, assinada em Paris, em 20 de outubro de 2005. Diário Oficial, Brasília, DF, [2007?].

ELIAS, Norbert; SCOTSON, John. Os estabelecidos e os outsiders: sociologia das relações de poder a partir de uma pequena comunidade. Rio de Janeiro (RJ): Zahar, 2000.

ESPIG, Márcia Janete. Uma "ferrovia estratégica"? A atuação da Estrada de Ferro São Paulo - Rio Grande durante a Guerra do Contestado. In: VALENTINI, Delmir J., ESPIG, Márcia J. e MACHADO, Paulo P. (Org.). Nem fanáticos, nem jagunços: reflexões sobre o Contestado (1912-2012). UFPEL/CAPES. 2012.

R. Inter. Interdisc. INTERthesis, Florianópolis, v.11, n.2, p.204-228, Jul-Dez. 2014
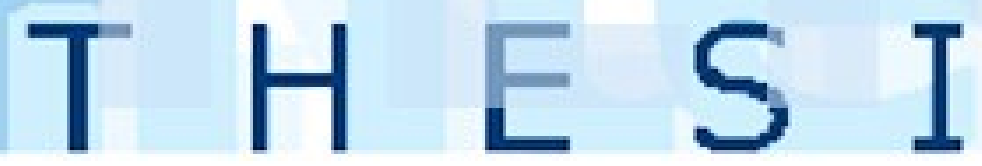
FRASER, Nancy. A Justiça Social na Globalização: redistribuição, reconhecimento e participação. Trad. por TAVARES, Teresa. In: Revista Crítica de Ciências Sociais, $n^{\circ} 63$, outubro de 2002.

GOFFMAN, Erving. Estigma: notas sobre a manipulação da identidade deteriorada. 4. ed. Rio de Janeiro (RJ): Guanabara, 1988.

LIFSCHITZ, Javier Alejandro. Neocomunidades: reconstruções de territórios e saberes. Estudos Históricos. Rio de Janeiro, n 38, p. 67-85, 2006.

MACHADO, Paulo Pinheiro. Invenção e tradição na formação das "Cidades Santas" do Contestado. Trabalho apresentado VIII Associação Latino-Americana de Sociologia Rural - ALASRU. PE: 2010.

MACHADO, Paulo Pinheiro. Lideranças do Contestado: a formação e a atuação das chefias caboclas (1912-1916). SP: Ed. Unicamp, 1 reimpressão, 2007.

MACHADO, Paulo Pinheiro. O Contestado e o mundo caboclo: História, Memória e Historiografia. In: VALENTINI, Delmir J., ESPIG, Márcia J. e MACHADO, Paulo P. (Org.). Nem fanáticos, nem jagunços: reflexões sobre o Contestado (19122012). UFPEL/CAPES. 2012.

MALINOWSKI, Bronislaw. Argonautas do pacífico ocidental: um relato do empreendimento e da aventura dos nativos nos arquipélagos da Nova Guiné Melanésia. 2a. ed. São Paulo: Abril Cultural, 1978. (Os pensadores).

MATTEI, Lauro. Pobreza rural: um fenômeno histórico-estrutural relacionado à estrutura agrária do país. RJ: OPPA-CPDA-UFRRJ, 2012.

MOTTA, Márcia. Dicionário da terra. Rio de Janeiro (RJ): Civilização Brasileira, 2005.

OLIVEIRA, Roberto Cardoso de. Caminhos da identidade: ensaios sobre etnicidade e multiculturalismo. São Paulo: Editora Unesp; Brasília, DF: Paralelo 15, 2006.

RAFFESTIN, Claude. Por uma geografia do poder. Volume 29. São Paulo: Ática, 1993.

R. Inter. Interdisc. INTERthesis, Florianópolis, v.11, n.2, p.204-228, Jul-Dez. 2014
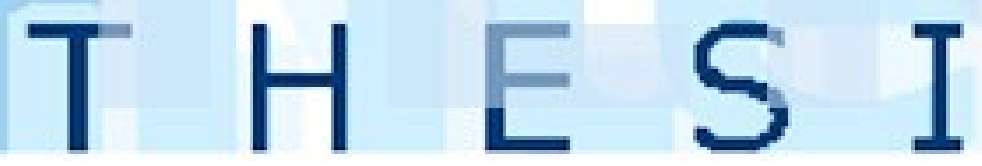
SABOURIN, Eric. Camponeses do Brasil: entre troca mercantil e reciprocidade. Rio de Janeiro: Ed. Garamond, 2009.

SANTOS, Milton. O retorno do território. In: OSAL - Observatório Social da América Latina. Ano 6, n 16. Buenos Aires: CLACSO, 2005.

SILVA, Ligia Osório. Terras devolutas e Latifúndio: Efeitos da lei de 1850. Campinas: Ed. da UNICAMP, 1996.

SILVA, Marcio Both. Por uma Lógica Camponesa: caboclos e imigrantes na formação do agro do planalto rio-grandense - 1850-1900. Dissertação (Mestrado em História) - Universidade Federal do Rio Grande do Sul, Porto Alegre, 2004.

SILVA, Tomaz Tadeu da. A produção social da identidade e da diferença. In: SILVA, Tomaz Tadeu da (org). Identidade e Diferença: a perspectiva dos Estudos Culturais. Petrópolis: Editora Vozes, 2005.

STROPASOLAS, Valmir Luiz. O mundo rural no horizonte dos jovens. Florianópolis, SC: Ed. da UFSC, 2006.

VENSON, Anamaria Marcon, PEDRO, Joana Maria. Memórias como fonte de pesquisa em história e antropologia. História Oral (Rio de Janeiro), v. 15, 2012.

ZARTH, Paulo Afonso. Do arcaico ao moderno: as transformações do Rio Grande do Sul rural no século XIX. ljuí: Ed. da Unijuí, 2002.

Artigo:

Recebido em Abril de 2014.

Aceito em Outubro de 2014

R. Inter. Interdisc. INTERthesis, Florianópolis, v.11, n.2, p.204-228, Jul-Dez. 2014
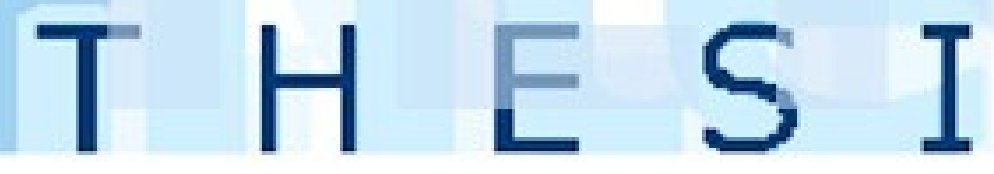